\title{
Article \\ Hypercrosslinked Ionic Polymers with High Ionic Content for Efficient Conversion of Carbon Dioxide into Cyclic Carbonates
}

\author{
Xu Liao ${ }^{1,+}$, Baoyou Pei ${ }^{2,+}$, Ruixun Ma ${ }^{2}$, Lingzheng Kong ${ }^{2}$, Xilin Gao ${ }^{1}$, Jiao He ${ }^{1}$, Xiaoyan Luo ${ }^{1, *}$ \\ and Jinqing $\operatorname{Lin} 1, * \mathbb{D}$ \\ 1 College of Materials Science and Engineering, Huaqiao University, Xiamen 361021, China; \\ liaoxu@stu.hqu.edu.cn (X.L.); gaoxilin@stu.hqu.edu.cn (X.G.); hejiao@stu.hqu.edu.cn (J.H.) \\ 2 College of Chemical Engineering, Huaqiao University, Xiamen 361021, China; \\ pbylt1314@stu.hqu.edu.cn (B.P.); maruixun@foxmail.com (R.M.); konglingzheng@stu.hqu.edu.cn (L.K.) \\ * Correspondence: chemistrylxy@163.com (X.L.); linlab@hqu.edu.cn (J.L.) \\ + These authors contributed equally to this work.
}

check for updates

Citation: Liao, X.; Pei, B.; Ma, R.;

Kong, L.; Gao, X.; He, J.; Luo, X.; Lin, J. Hypercrosslinked Ionic Polymers with High Ionic Content for Efficient Conversion of Carbon Dioxide into Cyclic Carbonates. Catalysts 2022, 12, 62. https://doi.org/10.3390/ catal12010062

Academic Editors: Vincenzo Vaiano and Olga Sacco

Received: 28 November 2021

Accepted: 31 December 2021

Published: 6 January 2022

Publisher's Note: MDPI stays neutral with regard to jurisdictional claims in published maps and institutional affiliations.

Copyright: (c) 2022 by the authors. Licensee MDPI, Basel, Switzerland. This article is an open access article distributed under the terms and conditions of the Creative Commons Attribution (CC BY) license (https:// creativecommons.org/licenses/by/ $4.0 /)$.

\begin{abstract}
The effective conversion of carbon dioxide $\left(\mathrm{CO}_{2}\right)$ into cyclic carbonates requires porous materials with high ionic content and large specific surface area. Herein, we developed a new systematic post-synthetic modification strategy for synthesizing imidazolium-based hypercrosslinked ionic polymers (HIPs) with high ionic content (up to $2.1 \mathrm{mmol} \mathrm{g}^{-1}$ ) and large specific surface area (385 $\mathrm{m}^{2}$ $\mathrm{g}^{-1}$ ) from porous hypercrosslinked polymers (HCPs) through addition reaction and quaternization. The obtained HIPs were efficient in $\mathrm{CO}_{2}$ capture and conversion. Under the synergistic effect of high ionic content, large specific surface area, and plentiful micro/mesoporosity, the metal-free catalyst [HCP-CH$-\mathrm{Cm}][\mathrm{Cl}]-1$ exhibited quantitative selectivities, high catalytic yields, and good substrate compatibility for the conversion of $\mathrm{CO}_{2}$ into cyclic carbonates at atmospheric pressure $(0.1 \mathrm{MPa})$ in a shorter reaction time in the absence of cocatalysts, solvents, and additives. High catalytic yields (styrene oxide, $120^{\circ} \mathrm{C}, 8 \mathrm{~h}, 94 \%$ yield; $100{ }^{\circ} \mathrm{C}, 20 \mathrm{~h}, 93 \%$ yield) can be achieved by appropriately extending the reaction times at low temperature, and the reaction times are shorter than other porous materials under the same conditions. This work provides a new strategy for synthesizing an efficient metal-free heterogeneous catalyst with high ionic content and a large specific surface area from HCPs for the conversion of $\mathrm{CO}_{2}$ into cyclic carbonates. It also demonstrates that the ionic content and specific surface area must be coordinated to obtain high catalytic activity for $\mathrm{CO}_{2}$ cycloaddition reaction.
\end{abstract}

Keywords: hypercrosslinked ionic polymers; high ionic content; $\mathrm{CO}_{2}$ cycloaddition; cyclic carbonates

\section{Introduction}

The exploitation of effective strategies for $\mathrm{CO}_{2}$ capture, sequestration, and utilization is crucial for the sustainable development of human society. An attractive and promising method is the utilization of $\mathrm{CO}_{2}$ as an abundant, low-cost, and renewable $\mathrm{C} 1$ resource to produce high value-added chemicals [1-5]. The $\mathrm{CO}_{2}$ cycloaddition reaction has elicited widespread attention because the reaction is $100 \%$ atom-economic [6]. In addition, the produced cyclic carbonates have extensive potential applications as polar aprotic solvents, electrolytes for lithium-ion cells and batteries, and intermediates [7].

To date, a large number of homogeneous and heterogeneous catalysts have been used for the $\mathrm{CO}_{2}$ cycloaddition reaction, including ionic liquids (ILs) [8-11], metal complexes [12-15], metal-organic frameworks (MOFs) [16-21], and porous organic polymers (POPs) [1-3,6,22-26]. Some strategies have been reported for homogeneous catalysts that catalyze the $\mathrm{CO}_{2}$ cycloaddition reaction, but these materials still face the issues of effective adsorption and catalyst recycling [27]. Additionally, metal catalysts can significantly improve catalytic activity for the $\mathrm{CO}_{2}$ cycloaddition reaction. Jiang et al. [28] developed a strategy to confine imidazolium-based poly(ionic liquid)s (denoted as polyILs) in the 
MOF material MIL-101 via in situ polymerization of encapsulated monomers. The resultant composite polyILs@MIL-101 with a large specific surface area $\left(2462 \mathrm{~m}^{2} \mathrm{~g}^{-1}\right)$ exhibited good $\mathrm{CO}_{2}$ capture and conversion capability at atmospheric pressure. However, the metal leaching and leftovers cause potential environmental pollution. Thus, developing effective and eco-friendly heterogeneous catalysts is necessary. The specific surface area and ionic content are important factors for the catalytic activity of porous materials. The poly(ionic liquid)s typically synthesized by free radical polymerization can have high ionic content, but they are mostly non-porous or low specific surface area materials. For example, Gai et al. [29] synthesized a new series of PIL-based copolymers through the free radical polymerization of ionic monomer and ethylene glycol dimethacrylate. The ionic content of PIL-4 reached up to $1.25 \mathrm{mmol} \mathrm{g}-1$ and the specific surface area was only $1.97 \mathrm{~m}^{2} \mathrm{~g}^{-1}$. PIL-4 catalyzed $\mathrm{CO}_{2}$ with epichlorohydrin into cyclic carbonate with $99 \%$ yield at $1 \mathrm{MPa} \mathrm{CO}_{2}, 100{ }^{\circ} \mathrm{C}$ in $12 \mathrm{~h}$. In addition, Yavuz et al. [30] reported an imidazolinium-based catalyst produced by a one-pot reaction of terephthalaldehyde and ammonium chloride; the obtained catalyst COP-222 had high ionic content $\left(4.05 \mathrm{mmol} \mathrm{g}^{-1}\right)$ and a small specific surface area $\left(21 \mathrm{~m}^{2}\right.$ $\left.\mathrm{g}^{-1}\right)$. COP-222 catalyzed epichlorohydrin with $\mathrm{CO}_{2}$ into cyclic carbonates with a $99 \%$ yield at $0.1 \mathrm{MPa} \mathrm{CO} \mathrm{CO}_{2}, 100{ }^{\circ} \mathrm{C}$ in $24 \mathrm{~h}$. The high pressure and long reaction time were needed due to the small specific surface area of catalysts.

The low-cost hypercrosslinked polymers (HCPs) are promising candidate materials for $\mathrm{CO}_{2}$ capture and conversion due to their exceptional advantages of large specific surface area and mild synthesis conditions. However, nonionic HCPs have few active functionalized sites, limiting their further application to the conversion of $\mathrm{CO}_{2}$. Therefore, the ILs were inserted into the porous HCPs through post-functionalization strategies to obtain HIPs, which combine the advantages of HCPs and ILs. Therefore, the HIPs are widely used for $\mathrm{CO}_{2}$ and conversion, adsorption of organic pollutants [31], and separation of bioactive molecules [32], etc. The large specific surface area and high microporosity of HCPs are efficient for $\mathrm{CO}_{2}$ capture, and ILs can provide the catalytic active site for the conversion of $\mathrm{CO}_{2}$. HIPs are synthesized mainly through the crosslinking of ionic and neutral monomers, in situ generations of ionic sites in the hypercrosslinked process, and post-functionalization strategies. Gai et al. [33] reported a strategy for synthesizing a series of novel HIPs via the Friedel-Crafts reaction of 2-phenylimidazole with $\alpha, \alpha^{\prime}$-dichloro-pxylene (DCX). The best active catalyst HP-[BZPhIm]Cl-DCX-1 has a large specific surface area $\left(763 \mathrm{~m}^{2} \mathrm{~g}^{-1}\right)$ and moderate IL content $\left(0.762 \mathrm{mmol} \mathrm{g}^{-1}\right)$. It can convert epichlorohydrin into cyclic carbonates with $99 \%$ yield and $98 \%$ selectivity at $120{ }^{\circ} \mathrm{C}, 0.1 \mathrm{MPa} \mathrm{CO}$ in 11 h. At present, there are few reports on the strategy of synthesizing HIPs from HCPs. Zhang et al. [34] developed a series of imidazolium-salt-modified porous HIPs through Friedel-Crafts alkylation and quaternization. The dichloroethane was used as crosslinker and solvent to construct the skeleton of HCPs containing methyl chloride, which further reacted with N-methylimidazole to form HIPs; the specific surface area and ionic content of as-prepared POM3-IM were $575 \mathrm{~m}^{2} \mathrm{~g}^{-1}$ and $1.01 \mathrm{mmol} \mathrm{g}{ }^{-1}$, respectively. The resultant catalyst exhibited an $89 \%$ yield for the conversion of styrene oxide into cyclic carbonates at $120{ }^{\circ} \mathrm{C}$ for $12 \mathrm{~h}$ under $1 \mathrm{MPa} \mathrm{CO}_{2}$. Although the aforementioned porous catalysts exhibited high catalytic yields for the cycloaddition of $\mathrm{CO}_{2}$ with epoxides, they require harsh reaction conditions (high pressure or longer reaction time at low pressure). The primary reason is that the specific surface area and ionic content of HIPs are contradictory during the preparation process, resulting in HIPs either with a large specific surface area but excessively low ionic content or high ionic content but excessively small specific surface area. Therefore, the development of a new strategy for synthesizing HIP catalysts with high ionic content and large specific surface area is imminent.

In the current work, we developed a new strategy for synthesizing HIPs with high ionic content and large specific surface area from HCPs through addition reaction and quaternization. The synthesis route of $\left[\mathrm{HCP}-\mathrm{CH}_{2}-\mathrm{Im}\right][\mathrm{Cl}]-\mathrm{X}$ is shown in Scheme 1 . In the first step, the HCP skeleton was constructed through the Friedel-Crafts alkylation reaction of diphenyl. In the second step, the prepared HCP reacts with allyl chloride to produce HCPs 
with chloromethyl groups, and the addition reaction conditions (mass ratio of allyl chloride to $\mathrm{HCP}$, mass ratio of $\mathrm{H}_{2} \mathrm{SO}_{4} / \mathrm{HCP}$, reaction time, and temperature) were changed to adjust the chloromethyl content and specific surface area of HCPs. Finally, a series of imidazoliumbased HIPs was prepared through quaternization with methylimidazole. The obtained $\left[\mathrm{HCP}-\mathrm{CH}_{2}-\mathrm{Im}\right][\mathrm{Cl}]-\mathrm{X}$ with high ionic content and large specific surface area catalyzed cycloaddition of $\mathrm{CO}_{2}$ with epoxides; the reaction conditions (dosage of catalyst, reaction temperature, and reaction time) were systematically studied to obtain the optimal reaction conditions. Additionally, a range of epoxides with important industrial applications was tested to determine the universality of $\left[\mathrm{HCP}-\mathrm{CH}_{2}-\mathrm{Im}\right][\mathrm{Cl}]-\mathrm{X}$ for $\mathrm{CO}_{2}$ cycloaddition reaction. The $\left[\mathrm{HCP}-\mathrm{CH}_{2}-\mathrm{Im}\right][\mathrm{Cl}]-\mathrm{X}$ was reused for several recycling to investigate the reusability of the catalyst. In conclusion, the HIPs with high ionic content and large specific surface area were synthesized for $\mathrm{CO}_{2}$ cycloaddition at atmospheric pressure in a short reaction. In addition, we found that the coordination of ionic content and specific surface area is a crucial factor to achieve high catalytic activity.

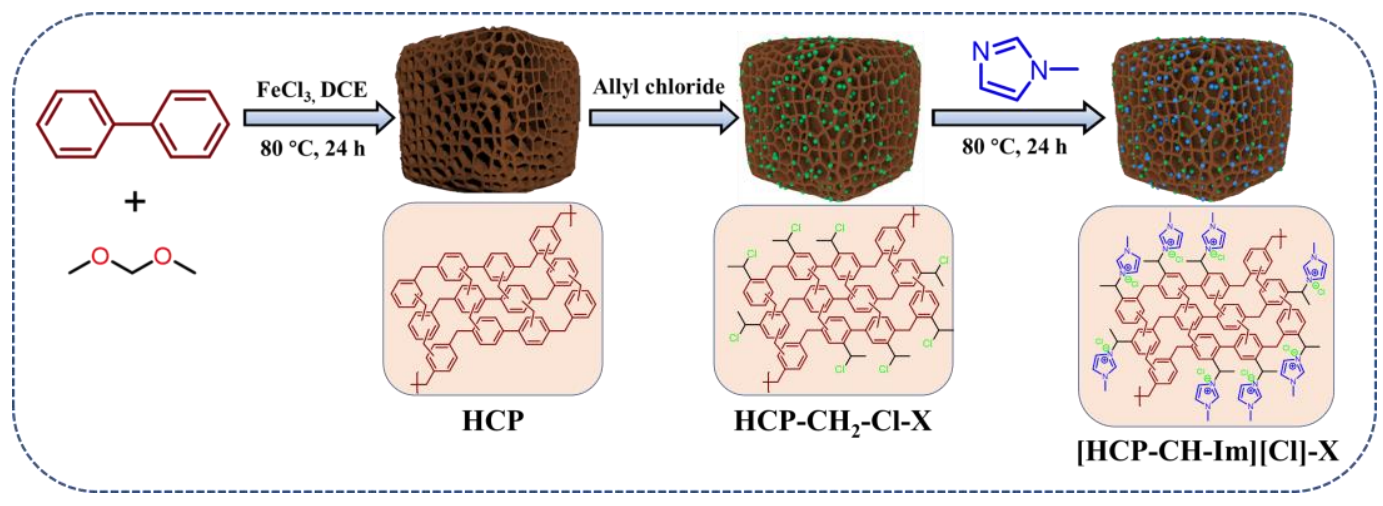

Scheme 1. Preparation of imidazolium-based hypercrosslinked ionic polymer [HCP-CH$-\mathrm{Im}][\mathrm{Cl}]-\mathrm{X}$ (X: different reaction conditions).

\section{Results and Discussion}

\subsection{Influences of Addition Reaction Conditions on Chloromethyl Content and Specific Surface Area}

The HCP skeleton was constructed through the Friedel-Crafts alkylation reaction of diphenyl and FDA; the specific surface area is $1153 \mathrm{~m}^{2} \mathrm{~g}^{-1}$. Although the specific surface areas will gradually decrease during the addition reaction and quaternization processes, the high specific surface area of HCP will provide a favorable guarantee for obtaining HIPs with high specific surface area. The addition reaction was carried out with active hydrogen on the benzene ring in the HCP skeleton by using allyl chloride as the chlorine source to produce a series of HCPs containing chloromethyl group, denoted as $\mathrm{HCP}-\mathrm{CH}_{2}-\mathrm{Cl}-\mathrm{X}$.

To obtain $\mathrm{HCP}-\mathrm{CH}_{2}-\mathrm{Cl}-\mathrm{X}$ with high chloromethyl content and larger specific surface area, the influences of addition reaction conditions, including the mass ratio of allyl chloride to $\mathrm{HCP}$, the mass ratio of $\mathrm{H}_{2} \mathrm{SO}_{4}$ to $\mathrm{HCP}$, reaction time and temperature on chloromethyl content, and specific surface area were investigated. As shown in Figure 1a and Table S1, the effect of the mass ratio of allyl chloride to HCP was discussed. The results show that the chloromethyl content reaches the maximum $\left(3.1 \mathrm{mmol} \mathrm{g}^{-1}\right)$ when the mass ratio of allyl chloride to HCP was increased to 5 . However, when the mass ratio of allyl chloride to HCP increased from 5 to 9 , the chloromethyl content decreased to $2.3 \mathrm{mmol} \mathrm{g}^{-1}$ because the excess allyl chloride causes the dilution of catalyst $\left(\mathrm{H}_{2} \mathrm{SO}_{4}\right)$. Furthermore, with the increase of the mass ratio of allyl chloride to HCP, the specific surface areas constantly decreased due to the pore being occupied by the grafted chloromethyl. Then, on this basis, other addition reaction conditions were further studied. 

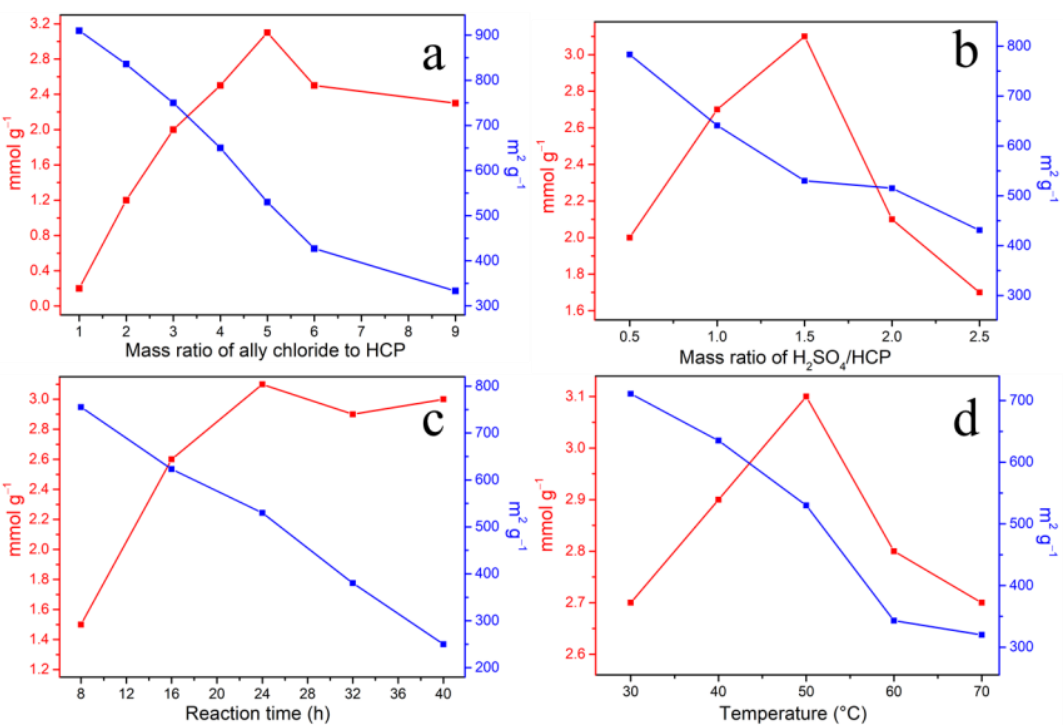

Figure 1. Effects of reaction conditions on specific surface area and content of the chloromethyl group of $\mathrm{HCP}-\mathrm{CH}_{2}-\mathrm{Cl}$ : (a) mass ratio of ally chloride to $\mathrm{HCP}$, mass ratio of $\mathrm{H}_{2} \mathrm{SO}_{4} / \mathrm{HCP}=1.5,50{ }^{\circ} \mathrm{C}$, $24 \mathrm{~h}$; (b) mass ratio of $\mathrm{H}_{2} \mathrm{SO}_{4} / \mathrm{HCP}$, mass ratio of ally chloride to $\mathrm{HCP}=5,50{ }^{\circ} \mathrm{C}, 24 \mathrm{~h}$; (c) reaction time, mass ratio of ally chloride to $\mathrm{HCP}=5$, mass ratio of $\mathrm{H}_{2} \mathrm{SO}_{4} / \mathrm{HCP}=1.5,50{ }^{\circ} \mathrm{C}$; (d) reaction temperature, mass ratio of ally chloride to $\mathrm{HCP}=5$, mass ratio of $\mathrm{H}_{2} \mathrm{SO}_{4} / \mathrm{HCP}=1.5,24 \mathrm{~h}$.

The experimental results (Figure $1 \mathrm{~b}$ and Table $\mathrm{S} 2$ ) show that when increasing the mass ratio of $\mathrm{H}_{2} \mathrm{SO}_{4} / \mathrm{HCP}$ from 0.5 to 1.5 , a positive effect was achieved on the chloromethyl content of $\mathrm{HCP}-\mathrm{CH}_{2}-\mathrm{Cl}-\mathrm{X}\left(2.0-3.1 \mathrm{mmol} \mathrm{g}^{-1}\right)$. However, when the mass ratio of $\mathrm{H}_{2} \mathrm{SO}_{4} / \mathrm{HCP}$ increased to 2.5 , the chloromethyl contents decreased to $1.7 \mathrm{mmol} \mathrm{g}^{-1}$ because the excessive sulfuric acid generated more sulfonation reactions of the benzene ring of $\mathrm{HCP}$, resulting in the passivation of the benzene ring and decreasing the chloromethyl content [35]. In addition, the specific surface area of $\mathrm{HCP}-\mathrm{CH}_{2}-\mathrm{Cl}-\mathrm{X}$ decreased from $783 \mathrm{~m}^{2} \mathrm{~g}^{-1}$ to $530 \mathrm{~m}^{2}$ $\mathrm{g}^{-1}$ when the mass ratio of $\mathrm{H}_{2} \mathrm{SO}_{4} / \mathrm{HCP}$ increased from 0.5 to 1.5 , which was attributed to the numerous pores that were occupied by the grafted chloromethyl group. With the increase of the mass ratio of $\mathrm{H}_{2} \mathrm{SO}_{4} / \mathrm{HCP} 2.5$, the specific surface area was further decreased due to the pores that were occupied after sulfonation.

The results presented in Figure 1c and Table S3 show that a reaction time of $24 \mathrm{~h}$ is appropriate, and the highest chloromethyl content $\left(3.1 \mathrm{mmol} \mathrm{g}^{-1}\right)$ was obtained. However, due to the side reaction of allyl chloride carbonization, the specific surface area was significantly reduced from $755 \mathrm{~m}^{2} \mathrm{~g}^{-1}$ to $250 \mathrm{~m}^{2} \mathrm{~g}^{-1}$ when the reaction time was prolonged. The effect of the reaction temperatures on the chloromethyl content and specific surface area of $\mathrm{HCP}-\mathrm{CH}_{2}-\mathrm{Cl}-\mathrm{X}$ are shown in Figure $1 \mathrm{~d}$ and Table S4. When the reaction temperature increased from $30^{\circ} \mathrm{C}$ to $50^{\circ} \mathrm{C}$, the chloromethyl content gradually increased. However, the grafting amount of chloromethyl exhibited a downward trend when the temperature was higher than $50^{\circ} \mathrm{C}$ because the addition reaction is exothermic. Furthermore, the specific surface area of $\mathrm{HCP}-\mathrm{CH}_{2}-\mathrm{Cl}-\mathrm{X}$ was reduced when increasing the reaction temperature. The reason for this phenomenon is similar to that for the change in reaction time. The optimal addition reaction conditions were identified as follows: the mass ratio of allyl chloride to $\mathrm{HCP}(5)$, the mass ratio of $\mathrm{H}_{2} \mathrm{SO}_{4} / \mathrm{HCP}(1.5)$, reaction time $(24 \mathrm{~h})$, and temperature $\left(50{ }^{\circ} \mathrm{C}\right)$; the chloromethyl content and specific surface area of $\mathrm{HCP}-\mathrm{CH}_{2}-\mathrm{Cl}-1$ can reach $2.1 \mathrm{mmol}$ $\mathrm{g}^{-1}$ and $385 \mathrm{~m}^{2} \mathrm{~g}^{-1}$, respectively. The $\mathrm{HCP}-\mathrm{CH}_{2}-\mathrm{Cl}-\mathrm{X}$ with high chloromethyl content was obtained for the following reasons: (1) the benzene ring in the HCP framework contains abundant active sites for addition reaction; (2) the active hydrogens have been fully utilized under the optimal reaction conditions. Additionally, the $\mathrm{HCP}-\mathrm{CH}_{2}-\mathrm{Cl}-\mathrm{X}$ with a large specific surface area or high chloromethyl content was selected for further quaternization reaction, denoted by $\mathrm{HCP}-\mathrm{CH}_{2}-\mathrm{Cl}-1-7$. The synthesis conditions of $\mathrm{HCP}-\mathrm{CH}_{2}-\mathrm{Cl}-1-7$ are shown in Table S5. 


\subsection{The Effects of Ionic Content and Specific Surface Area on Catalytic Activity}

The corresponding $\mathrm{HCP}-\mathrm{CH}_{2}-\mathrm{Cl}-\mathrm{X}$ reacted with methylimidazole to produce various HIPs ([HCP- $\left.\left.\mathrm{CH}_{2}-\mathrm{Im}\right][\mathrm{Cl}]-\mathrm{X}\right)$ with different ionic content and specific surface area. The catalyst [HCP- $\left.\mathrm{CH}_{2}-\mathrm{Im}\right][\mathrm{Cl}]-\mathrm{X}$ was used to catalyze the cycloaddition reaction of $\mathrm{CO}_{2}$ with styrene epoxide (SO) at $140^{\circ} \mathrm{C}, 0.1 \mathrm{MPa}$ in $4 \mathrm{~h}$. As indicated in Table 1 , [HCP-CH$\left.-\mathrm{Cm}\right][\mathrm{Cl}]-\mathrm{X}$ can effectively catalyze the cycloaddition of $\mathrm{CO}_{2}$ with $\mathrm{SO}$, and the selectivity of all the catalysts is beyond $99 \%$. The production of styrene carbonate was negligible by using the nonionic $\mathrm{HCP}$ (entry 1, 5\%) and $\mathrm{HCP}-\mathrm{CH}_{2}-\mathrm{Cl}-1$ (entry 2, 7\%) as catalysts. The catalysts with low ionic content and small specific surface area exhibited worse yields (entries 5, 7, and 9: $74 \%, 72 \%$, and $72 \%$ yields, respectively). The higher yields were achieved for catalysts with low ionic content and large specific surface area under identical reaction conditions (entries 4,6 , and $8: 89 \%, 88 \%$, and $84 \%$ yields, respectively). The comparison of entry 8 with entry 7 shows that the larger specific surface area $\left(406 \mathrm{~m}^{2} \mathrm{~g}^{-1}\right.$ versus $\left.183 \mathrm{~m}^{2} \mathrm{~g}^{-1}\right)$ presented a higher yield ( $84 \%$ versus $72 \%$ ) when the catalysts with the same ionic content because of the larger specific surface area can concentrate more $\mathrm{CO}_{2}$ molecule. Entry 3 and entry 5 show that when the specific surface area of the catalysts is nearly the same, the yield of catalysts with higher ionic content is higher ( $95 \%$ versus $74 \%$ ). In addition, the catalyst with higher ionic content (entry 7,1.65 $\left.\mathrm{mmol} \mathrm{g}^{-1}\right)$ but a tiny specific surface area $\left(183 \mathrm{~m}^{2}\right.$ $\mathrm{g}^{-1}$ ) exhibited lower yield (72\%) than the catalysts with lower ionic content (entries 4, 5 , and 6: $0.99,0.48$, and $0.85 \mathrm{mmol} \mathrm{g}^{-1}$, respectively) but a larger specific surface area (510, 386 , and $503 \mathrm{~m}^{2} \mathrm{~g}^{-1}$, respectively) under identical reaction conditions. Notably, the catalyst [HCP-CH $-\mathrm{Cm}][\mathrm{Cl}]-1$ with the highest ionic content and higher specific surface area has the highest yield of $95 \%$ (entry 3 ). The experimental results indicated that catalysts with excessively low ionic content or small specific surface area are not conducive to the $\mathrm{CO}_{2}$ cycloaddition reaction; the high catalytic activity requires high ionic content, large specific surface area, and the coordination of them to achieve efficient catalysis. The catalytic activity and characterization of the catalyst $\left[\mathrm{HCP}-\mathrm{CH}_{2}-\mathrm{Im}\right][\mathrm{Cl}]-1$ were further studied.

Table 1. Cycloaddition of $\mathrm{CO}_{2}$ with styrene oxide.

\begin{tabular}{|c|c|c|c|c|c|}
\hline Entry & Sample ${ }^{a}$ & $\begin{array}{c}\text { IL Content }^{\mathrm{b}} \\
\left(\mathrm{mmol} \mathrm{g}^{-1}\right)\end{array}$ & $\begin{array}{c}\mathrm{S}_{\mathrm{BET}}{ }^{\mathrm{c}}\left(\mathrm{m}^{2}\right. \\
\left.\mathrm{g}^{-1}\right)\end{array}$ & Yield $^{\mathrm{d}}(\%)$ & Sel. ${ }^{d}(\%)$ \\
\hline 1 & HCP & - & 1153 & 5 & 99 \\
\hline 2 & $\mathrm{HCP}-\mathrm{CH}_{2}-\mathrm{Cl}-1$ & - & 530 & 7 & 99 \\
\hline 3 & $\begin{array}{c}{\left[\mathrm{HCP}-\mathrm{CH}_{2-}\right.} \\
\mathrm{Im}][\mathrm{Cl}]-1\end{array}$ & 2.10 & 385 & 95 & $>99$ \\
\hline 4 & $\begin{array}{l}{\left[\mathrm{HCP}-\mathrm{CH}_{2-}\right.} \\
\mathrm{Im}][\mathrm{Cl}]-2\end{array}$ & 0.99 & 510 & 89 & $>99$ \\
\hline 5 & $\begin{array}{l}{\left[\mathrm{HCP}-\mathrm{CH}_{2}-\right.} \\
\mathrm{Im}][\mathrm{Cl}]-3\end{array}$ & 0.48 & 386 & 74 & 99 \\
\hline 6 & $\begin{array}{l}{\left[\mathrm{HCP}-\mathrm{CH}_{2}-\right.} \\
\mathrm{Im}][\mathrm{Cl}]-4\end{array}$ & 0.85 & 503 & 88 & $>99$ \\
\hline 7 & $\begin{array}{l}{\left[\mathrm{HCP}-\mathrm{CH}_{2}-\right.} \\
\mathrm{Im}][\mathrm{Cl}]-5\end{array}$ & 1.65 & 183 & 72 & 99 \\
\hline 8 & $\begin{array}{l}{\left[\mathrm{HCP}-\mathrm{CH}_{2-}\right.} \\
\mathrm{Im}][\mathrm{Cl}]-6\end{array}$ & 1.81 & 406 & 84 & $>99$ \\
\hline 9 & $\begin{array}{l}{\left[\mathrm{HCP}-\mathrm{CH}_{2-}\right.} \\
\mathrm{Im}][\mathrm{Cl}]-7\end{array}$ & 1.26 & 295 & 72 & 99 \\
\hline
\end{tabular}

${ }^{a}$ Reaction condition: $5 \mathrm{mmol}$ styrene oxide, catalyst $(25 \mathrm{wt} \%), \mathrm{CO}_{2}(0.1 \mathrm{MPa}), 140{ }^{\circ} \mathrm{C}, 4 \mathrm{~h} .{ }^{\mathrm{b}} \mathrm{IL}$ content calculated by elemental analysis. ${ }^{\mathrm{c}}$ BET specific surface area. ${ }^{\mathrm{d}}$ Yield and selectivity were determined by $1 \mathrm{H}$ NMR.

\subsection{Characterization of Polymers}

The Fourier transform infrared (FTIR) spectra of HCP (a), $\mathrm{HCP}-\mathrm{CH}_{2}-\mathrm{Cl}-1$ (b), and $\left[\mathrm{HCP}-\mathrm{CH}_{2}-\mathrm{Im}\right][\mathrm{Cl}]-1$ (c) are shown in Figure 2. The (b) exhibited a characteristic peak at $617 \mathrm{~cm}^{-1}$, which belonged to the vibrative absorption of $\mathrm{C}-\mathrm{Cl}$ [36]. The absorption of $\mathrm{C}-\mathrm{Cl}$ weakened and the characteristic peak of the imidazolium ring appeared at $1598 \mathrm{~cm}^{-1}$ and $1167 \mathrm{~cm}^{-1}$ after quaternization, which belonged to the imidazolium ring stretching of $\mathrm{C}=\mathrm{N}$ and $\mathrm{C}-\mathrm{N}$, respectively $[1,6,37]$. The preceding results indicated that imidazolium-based HIPs were successfully prepared. The thermogravimetric analysis (TGA) curves of HCP, 
$\mathrm{HCP}-\mathrm{CH}_{2}-\mathrm{Cl}-1$, and [HCP-CH$\left.-\mathrm{Cm}\right][\mathrm{Cl}]-1$ in Figure $3 \mathrm{a}$ illustrate that the catalysts exhibited favorable thermal stability. In particular, the weight loss of $\mathrm{HCP}, \mathrm{HCP}-\mathrm{CH}_{2}-\mathrm{Cl}-1$, and [HCP$\mathrm{CH}_{2}$-Im] [Cl]-1 started at $324^{\circ} \mathrm{C}, 360{ }^{\circ} \mathrm{C}$, and $236{ }^{\circ} \mathrm{C}$, respectively, which are considerably higher than the reaction temperature.

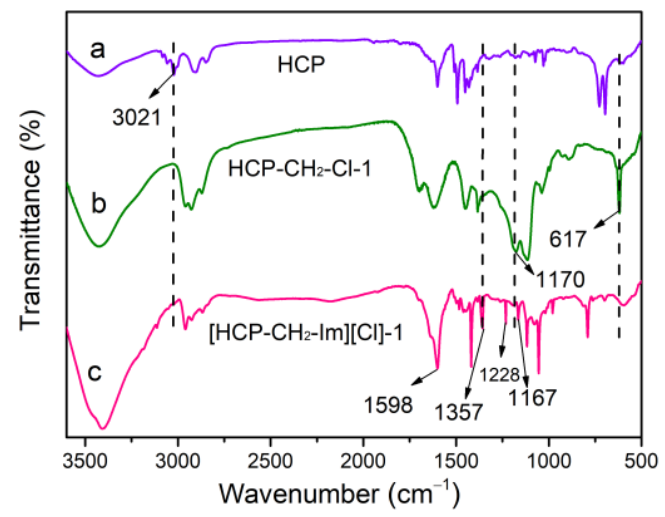

Figure 2. FT-IR spectra of (a) HCP, (b) $\mathrm{HCP}-\mathrm{CH}_{2}-\mathrm{Cl}-1$, and (c) $\left[\mathrm{HCP}-\mathrm{CH}_{2}-\mathrm{Im}\right][\mathrm{Cl}]-1$.
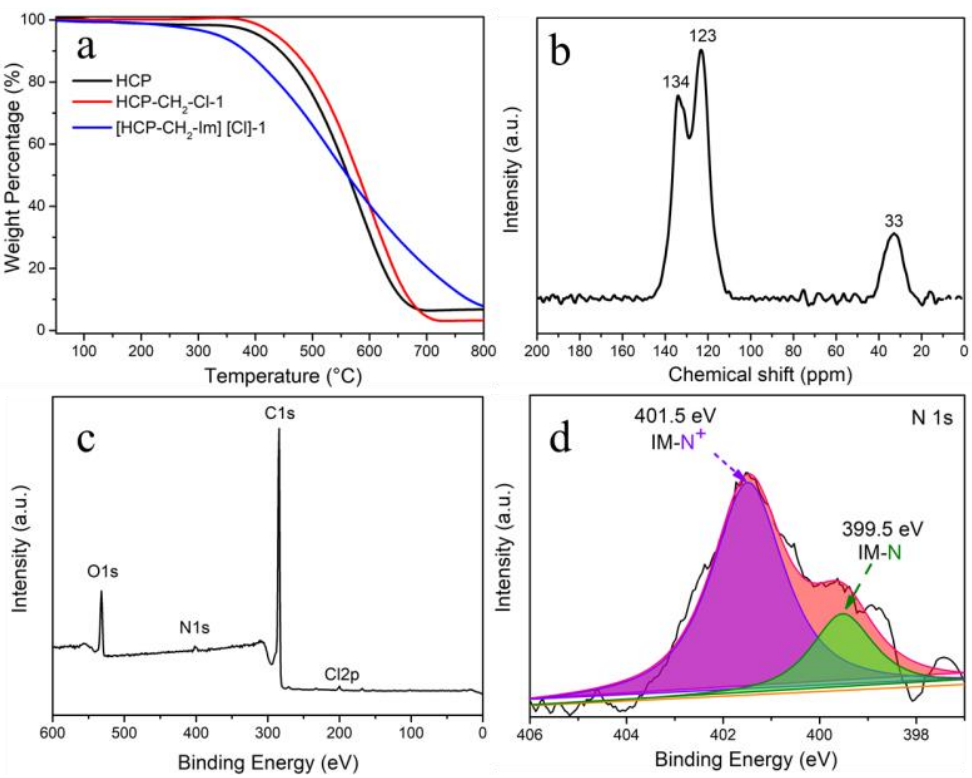

Figure 3. (a) TGA curves of $\mathrm{HCP}, \mathrm{HCP}-\mathrm{CH}_{2}-\mathrm{Cl}-1$, and $\left[\mathrm{HCP}-\mathrm{CH}_{2}-\mathrm{Im}\right][\mathrm{Cl}]-1$, (b) ${ }^{13} \mathrm{C} \mathrm{CP} / \mathrm{MAS}$ NMR spectrum of $\left[\mathrm{HCP}-\mathrm{CH}_{2}-\mathrm{Im}\right][\mathrm{Cl}]-1$, (c) survey scan, and (d) N 1 s XPS spectra of [HCP-CH $\left.-\mathrm{Im}\right][\mathrm{Cl}]-1$.

The $\left[\mathrm{HCP}-\mathrm{CH}_{2}-\mathrm{Im}\right][\mathrm{Cl}]-1$ sample was further characterized via solid-state ${ }^{13} \mathrm{C} \mathrm{NMR}$ and X-ray photoelectron spectroscopy (XPS). As shown in Figure 3b, the signals at 134 ppm and $123 \mathrm{ppm}$ belonged to the imidazole ring and aromatic carbons of the benzene ring, respectively. Meanwhile, the peak at 33 ppm originated from the methylene carbon formed via Friedel-Crafts reaction [34,38,39]. The survey scan XPS spectrum produced signals at $532.3,401.6,284.0,270.4$, and $199.8 \mathrm{eV}$, which belonged to the element species of $\mathrm{C} 1 \mathrm{~s}, \mathrm{O} 1 \mathrm{~s}$, $\mathrm{N} 1 \mathrm{~s}, \mathrm{Br} 3 \mathrm{~s}$, and $\mathrm{Cl} 2 \mathrm{p}$ (Figure 3c), respectively. The XPS of the $\mathrm{N}$ 1s of [ $\left.\mathrm{HCP}-\mathrm{CH}_{2}-\mathrm{Im}\right][\mathrm{Cl}]-1$ (Figure 3d) shows two peaks at $399.5 \mathrm{eV}$ and $401.5 \mathrm{eV}$, which are assigned to the nonionic $\mathrm{N}$ atoms and imidazolinium cations, respectively $[40,41]$. The preceding results indicate that imidazolium was successfully grafted onto the backbone of the HIP.

Scanning electron microscopy (SEM) images (Figure $4 a, b, e, f, i, j)$ showed that the polymers were composed of anomalistic nanoparticles at the micrometer level. Elemental mapping images (Figure $4 \mathrm{c}, \mathrm{d}, \mathrm{g}, \mathrm{h}, \mathrm{k}, \mathrm{l}$ ) showed that $\mathrm{Cl}$ and $\mathrm{N}$ were dispersed throughout the polymer skeleton, indicating that ionic sites were uniformly dispersed in the polymer 
skeleton. The $\mathrm{Cl}$ content was significantly increased after the addition reaction. Meanwhile, $\mathrm{N}$ content was significantly increased and $\mathrm{Cl}$ content remained unchanged after quaternization. These results further prove that the successful preparation of HIPs occurred. In addition, the aforementioned morphology of [HCP-CH$-\mathrm{Im}][\mathrm{Cl}]-1$ was illustrated through transmission electron microscopy images (Figure 5). X-ray diffraction patterns indicate that HCPs and HIPs were amorphous (Figure S1).

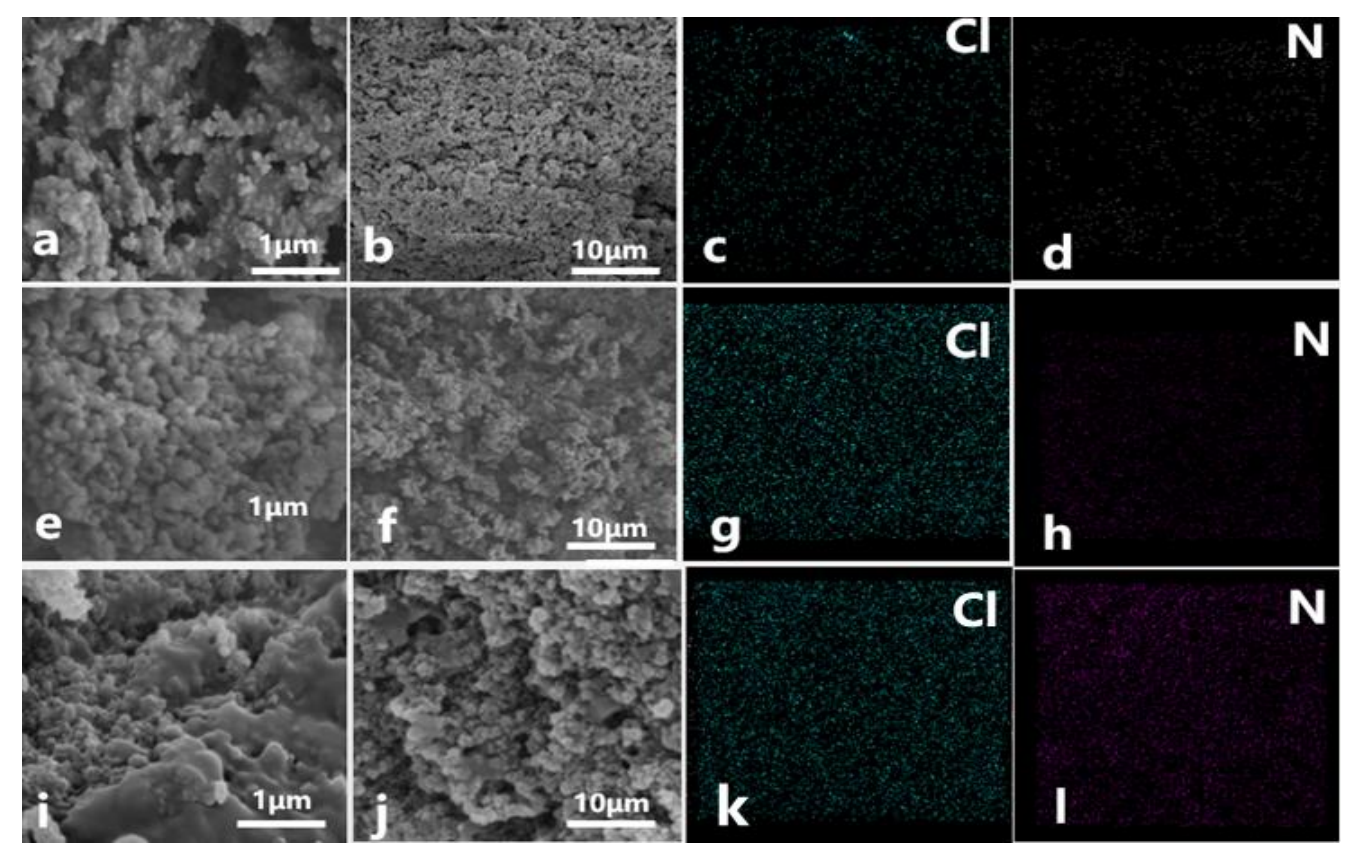

Figure 4. SEM images and elemental $(\mathrm{N}$ and $\mathrm{Cl})$ mapping images of $\mathrm{HCP}(\mathbf{a}-\mathbf{d}), \mathrm{HCP}-\mathrm{CH}_{2}-\mathrm{Cl}-1(\mathbf{e}-\mathbf{h})$, and $\left[\mathrm{HCP}-\mathrm{CH}_{2}-\mathrm{Im}\right][\mathrm{Cl}]-1$ (i-1).
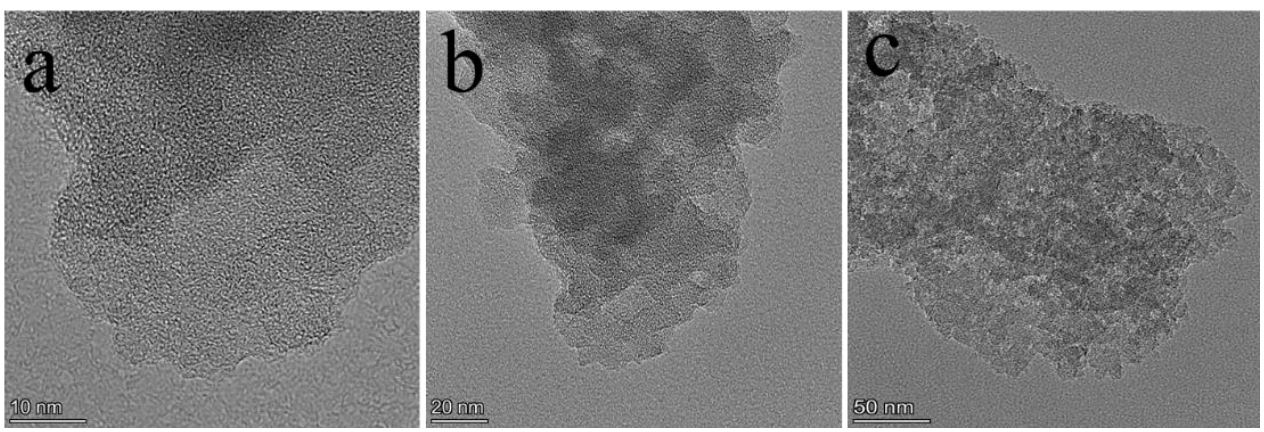

Figure 5. TEM images of [HCP-CH$-\mathrm{Cm}][\mathrm{Cl}]-1$ (a) $10 \mathrm{~nm}$; (b) $20 \mathrm{~nm}$; (c) $50 \mathrm{~nm}$ ).

The porosity of [HCP-CH$-\mathrm{Im}][\mathrm{Cl}]-\mathrm{X}$ was studied through $\mathrm{N}_{2}$ adsorption experiments. As shown in Figure 6a, the prepared [HCP-CH2-Im][Cl]-X presents typical Type IV isotherms [42] and the adsorption curve rose faster in the low-pressure area, which indicates that the material contained a certain number of microporous structures, which was conducive to $\mathrm{CO}_{2}$ concentration [43]. Furthermore, the pore size distribution diagram was calculated using the nonlocal density function in Figure 6b; the pores of the polymers were mostly concentrated at approximately $1 \mathrm{~nm}$ to $6 \mathrm{~nm}$ and are microporous/mesoporous structures. The existence of a mesoporous structure was beneficial for mass transfer and accelerated the reaction rate [44]. The morphological properties of $\left[\mathrm{HCP}-\mathrm{CH}_{2}-\mathrm{Im}\right][\mathrm{Cl}]-\mathrm{X}$ are summarized in Table S6 in accordance with the $\mathrm{N}_{2}$ isotherm; the $\left[\mathrm{HCP}-\mathrm{CH}_{2}-\mathrm{Im}\right][\mathrm{Cl}]-\mathrm{X}$ is primarily composed of microporous structures and a small number of mesoporous structures. Figure S2a shows that the $\mathrm{CO}_{2}$ isotherms of $\left[\mathrm{HCP}-\mathrm{CH}_{2}-\mathrm{Im}\right][\mathrm{Cl}]-1$ have relative pressure 
ranging from 0 bar to 1.0 bar at $273 \mathrm{~K}$ and $298 \mathrm{~K}$. The $\mathrm{CO}_{2}$ uptakes of [HCP-CH$\left.-\mathrm{Im}\right][\mathrm{Cl}]-1$ are $1.79 \mathrm{mmol} \mathrm{g}^{-1}(273 \mathrm{~K})$ and $1.20 \mathrm{mmol} \mathrm{g}^{-1}(298 \mathrm{~K})$. Moreover, Figure S2b illustrates that $\mathrm{CO}_{2}$ uptakes exhibited almost no decrease after adsorption-desorption was run five times, demonstrating excellent reusability.
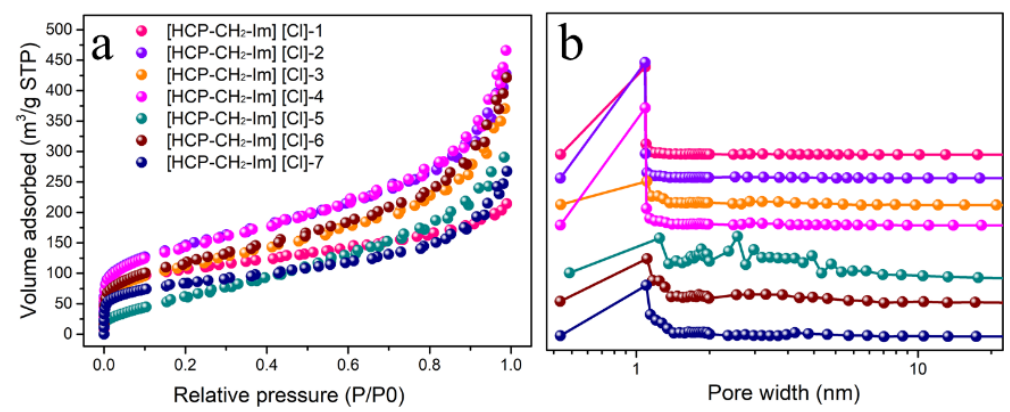

Figure 6. (a) $\mathrm{N}_{2}$ adsorption-desorption isotherms, (b) pore size distribution of [ $\left.\mathrm{HCP}-\mathrm{CH}_{2}-\mathrm{Im}\right][\mathrm{Cl}]-\mathrm{X}$.

\subsection{Optimization of Cycloaddition Reaction Conditions and the Universality of Catalysts}

The catalytic activity of [HCP-CH$-\mathrm{Im}][\mathrm{Cl}]-1$ was further studied to obtain the optimal reaction conditions for the cycloaddition of $\mathrm{CO}_{2}$ with epoxides. As shown in Figure 7, the effects of temperature, mass ratio of the catalyst to $\mathrm{SO}$, and reaction time on the catalytic activity of $\left[\mathrm{HCP}-\mathrm{CH}_{2}-\mathrm{Im}\right][\mathrm{Cl}]-1$ were investigated by using $\mathrm{SO}$ as substrate. The catalyst [HCP-CH $-\mathrm{Hm}][\mathrm{Cl}]-1$ exhibited high selectivity $(99 \%)$ under all reaction conditions. In Figure $7 \mathrm{a}$, the reaction temperature exerted a remarkable effect on the yields for the cycloaddition reaction. When the reaction temperature was increased within the range of 50 to $140{ }^{\circ} \mathrm{C}$, the yield of cyclic carbonate increased from $5 \%$ to $99 \%$, and then it became stable when the temperature was further increased to $150{ }^{\circ} \mathrm{C}$. When the mass ratio of the catalyst to SO increased from $0 \mathrm{wt} \%$ to $25 \mathrm{wt} \%$ (Figure $7 \mathrm{~b}$ ), carbonate yield constantly increased from 1\% to $99 \%$. Figure $7 \mathrm{c}$ shows the effect of reaction time at $140{ }^{\circ} \mathrm{C}, 25 \mathrm{wt} \%$ mass ratio of the catalyst to $\mathrm{SO}$, and $0.1 \mathrm{MPa} \mathrm{CO}_{2}$ on catalytic activity. Cyclic carbonate yield exhibited a gradual increase from $1 \mathrm{~h}$ to $5 \mathrm{~h}$ (yield from $62 \%$ to $99 \%$ ), and remained unchanged when the reaction time was increased to $6 \mathrm{~h}$. [HCP-CH$-\mathrm{Im}][\mathrm{Cl}]-1$ exhibited $99 \%$ yield and $99 \%$ selectivity for the cycloaddition of $\mathrm{CO}_{2}$ with $\mathrm{SO}$ under optimal reaction conditions $\left(0.1 \mathrm{MPa} \mathrm{CO}, 140{ }^{\circ} \mathrm{C}, 25 \mathrm{wt} \%\right.$ catalysts, $\left.5 \mathrm{~h}\right)$.

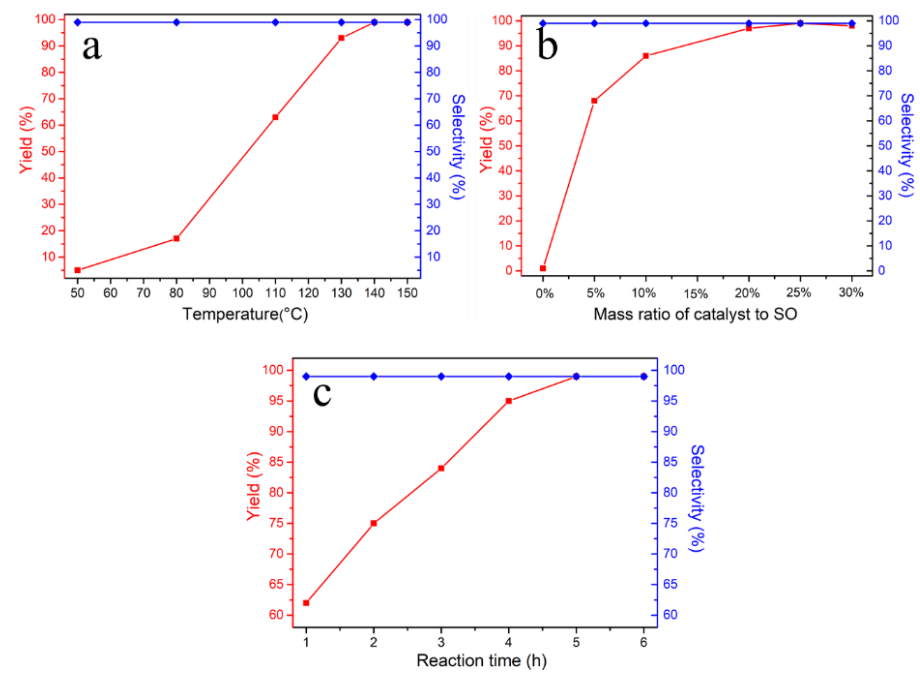

Figure 7. Effect of yield and selectivity as a function of (a) temperature, styrene oxide (5 mmol), $0.1 \mathrm{MPa} \mathrm{CO} 2,5 \mathrm{~h}$, [HCP-CH$-\mathrm{Im}][\mathrm{Cl}]-1$ (25 wt \%); (b) mass ratio of catalyst to $\mathrm{SO}$, styrene oxide (5 mmol), $0.1 \mathrm{MPa} \mathrm{CO}, 140{ }^{\circ} \mathrm{C}, 5 \mathrm{~h}$; (c) reaction time, styrene oxide $(5 \mathrm{mmol}), 0.1 \mathrm{MPa} \mathrm{CO}_{2}, 140{ }^{\circ} \mathrm{C}$, $\left[\mathrm{HCP}-\mathrm{CH}_{2}-\mathrm{Im}\right][\mathrm{Cl}]-1$ (25 wt\%). 
A range of epoxides with important industrial applications was tested to determine the universality of $\left[\mathrm{HCP}-\mathrm{CH}_{2}-\mathrm{Im}\right][\mathrm{Cl}]-1$ for $\mathrm{CO}_{2}$ cycloaddition reaction. All the examined substrates exhibited excellent yield and selectivity under optimal conditions as summarized in Table 2 . The yields of the products from propylene oxide, epichlorohydrin, and epibromohydrin reached $99 \%$ within $4 \mathrm{~h}$ (entries $1-3$ ). The catalytic activity of the catalyst [HCP-CH $-\mathrm{Im}][\mathrm{Cl}]-1$ for $\mathrm{SO}$ was further studied at lower temperatures; it can be found that excellent catalytic yields (entry 4) were achieved by slightly extending the reaction time at lower temperatures. Moreover, although less reactive substrates with long chains and oxymethylene moiety required a longer reaction time, excellent yields were still obtained at $140{ }^{\circ} \mathrm{C}, 0.1 \mathrm{MPa} \mathrm{CO}_{2}(6 \mathrm{~h}, 91-99 \%$, entries 5-8). The experimental results demonstrated that the catalyst [HCP-CH$-\mathrm{Im}][\mathrm{Cl}]-1$ exhibited excellent catalytic activity for similar substrates. The reaction time of the $\left[\mathrm{HCP}-\mathrm{CH}_{2}-\mathrm{Im}\right][\mathrm{Cl}]-1$ catalyst was compared with those of recently reported heterogeneous porous catalysts for the cycloaddition of $\mathrm{CO}_{2}$ with $\mathrm{SO}$ (Table S7). By contrast, $\left[\mathrm{HCP}-\mathrm{CH}_{2}-\mathrm{Im}\right][\mathrm{Cl}]-1$ required a shorter reaction time than the same type of catalysts under the same reaction conditions.

Table 2. Cycloaddition of $\mathrm{CO}_{2}$ to various epoxides catalyzed by $\left[\mathrm{HCP}-\mathrm{CH}_{2}-\mathrm{Im}\right][\mathrm{Cl}]-1$.

ENTRY ${ }^{A}$ SUbSTRATE

a Reaction condition: $5 \mathrm{mmol}$ epoxides, $\left[\mathrm{HCP}-\mathrm{CH}_{2}-\mathrm{Im}\right][\mathrm{Cl}]-1(25 \mathrm{wt} \%), \mathrm{CO}_{2}(0.1 \mathrm{MPa}), 140{ }^{\circ} \mathrm{C} .{ }^{\mathrm{b}}$ Yield and selectivity were determined by ${ }^{1} \mathrm{H}$ NMR. ${ }^{c}$ Isolate yield by recrystallization.

\subsection{Reusability of Catalysts}

The reusability of catalysts is an important factor in economic and industrial applications. To investigate the reusability of the HIP catalyst $\left[\mathrm{HCP}-\mathrm{CH}_{2}-\mathrm{Im}\right][\mathrm{Cl}]-1$, the SO was used as the substrate for cycloaddition reaction under optimal reaction conditions. After the reaction, ethyl acetate was added to separate the cyclic carbonates from the catalyst $\left[\mathrm{HCP}-\mathrm{CH}_{2}-\mathrm{Im}\right][\mathrm{Cl}]-1$ via filtration. Then the catalyst $\left[\mathrm{HCP}-\mathrm{CH}_{2}-\mathrm{Im}\right][\mathrm{Cl}]-1$ was dried under vacuum and applied in the next run. As shown in Figure $8 \mathrm{a}$, the catalyst was run six 
times and its catalytic activity did not drop significantly (90-99\% yield and 99\% selectivity). The slight decrease in catalytic activity due to catalyst loss during the separation process demonstrates the excellent reusability of the $\left[\mathrm{HCP}-\mathrm{CH}_{2}-\mathrm{Im}\right][\mathrm{Cl}]-1$. The stability of the catalyst $\left[\mathrm{HCP}-\mathrm{CH}_{2}-\mathrm{Im}\right][\mathrm{Cl}]-1$ after six run times was studied via SEM, FTIR, and TGA. The recycled catalyst $\left[\mathrm{HCP}-\mathrm{CH}_{2}-\mathrm{Im}\right][\mathrm{Cl}]-1$ showed a dense pore structure in the SEM image shown in Figure 8b. Furthermore, the characteristic peak of recycled catalyst presented no evident change in contrast with the FTIR spectrum of the fresh catalyst, and the newly emerged characteristic peaks $1790 \mathrm{~cm}^{-1}$ and $1672 \mathrm{~cm}^{-1}$ belong to cyclic carbonate (Figure 8c). As shown in Figure 8d, the stability of the catalyst was further examined through TGA. The thermal stability of the reused $\left[\mathrm{HCP}-\mathrm{CH}_{2}-\mathrm{Im}\right][\mathrm{Cl}]-1$ catalyst after six run times was as good as that of the fresh catalyst. These results proved that the recycled catalyst $\left[\mathrm{HCP}-\mathrm{CH}_{2}-\mathrm{Im}\right][\mathrm{Cl}]-1$ can meet the reaction temperature requirement.
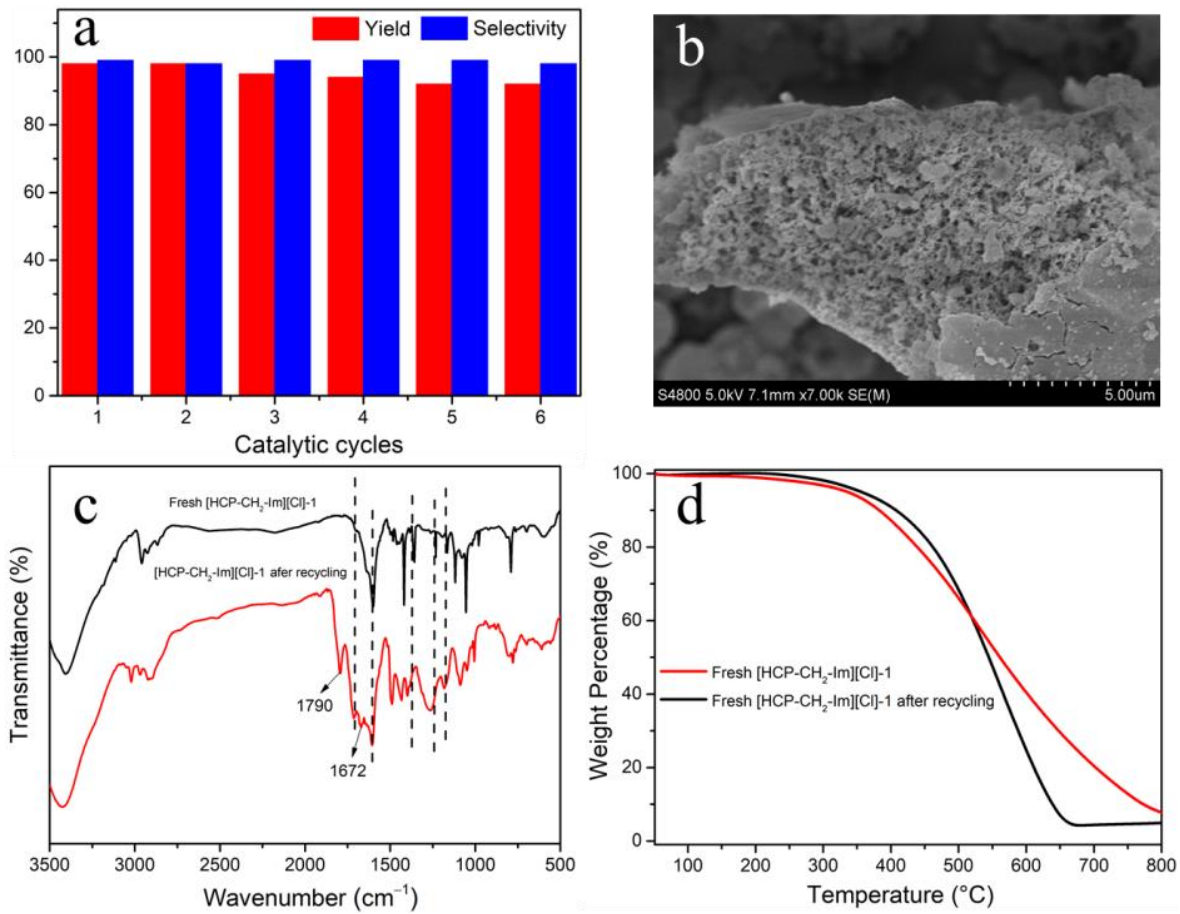

Figure 8. (a) Reusability of [HCP-CH$-\mathrm{Im}][\mathrm{Cl}]-1$ for $\mathrm{CO}_{2}$ cycloaddition with epichlorohydrin. Reaction conditions: styrene oxide $(5 \mathrm{mmol}), \mathrm{CO}_{2}(0.1 \mathrm{MPa})$, catalyst $(25 \mathrm{wt} \%), 140{ }^{\circ} \mathrm{C}, 5 \mathrm{~h},(\mathrm{~b}) \mathrm{SEM}$ image, (c) FT-IR spectrum, (d) TG curves of [HCP-CH$-\mathrm{Cm}][\mathrm{Cl}]-1$ after having been run 6 times.

\subsection{Proposed Mechanism}

The proposed catalytic mechanism of $\left[\mathrm{HCP}-\mathrm{CH}_{2}-\mathrm{Im}\right][\mathrm{Cl}]-1$ in catalyzing $\mathrm{CO}_{2}$ conversion into cyclic carbonates is illustrated in Scheme 2. In all the aforementioned steps, the step to determine the $\mathrm{CO}_{2}$ cycloaddition rate is typically known as the epoxy ring opening step $[45,46]$. As shown in Scheme 2, when the epoxide entered the pores of the catalyst, the $\mathrm{C}-\mathrm{O}$ bond of epoxide was activated by the interaction between the oxygen atom and imidazolium cation, accelerating the ring opening of the epoxide (Step 1) [25,47,48]. Meanwhile, the chloride anion of [HCP-CH $-\mathrm{Hm}][\mathrm{Cl}]-1$ attacked the $\alpha$-carbon atom of the epoxy ring to produce the ring opening intermediate (Step 2). Subsequently, $\mathrm{CO}_{2}$ was adsorbed by the $\left[\mathrm{HCP}-\mathrm{CH}_{2}-\mathrm{Im}\right][\mathrm{Cl}]-1$ and inserted into the strongly nucleophilic intermediate to generate cyclic esters (Step 3). Finally, cyclic carbonates were formed through the elimination of chloride ions and the intramolecular cyclization of acyclic ester (Step 4), followed by the regeneration of the catalyst for the next run. 


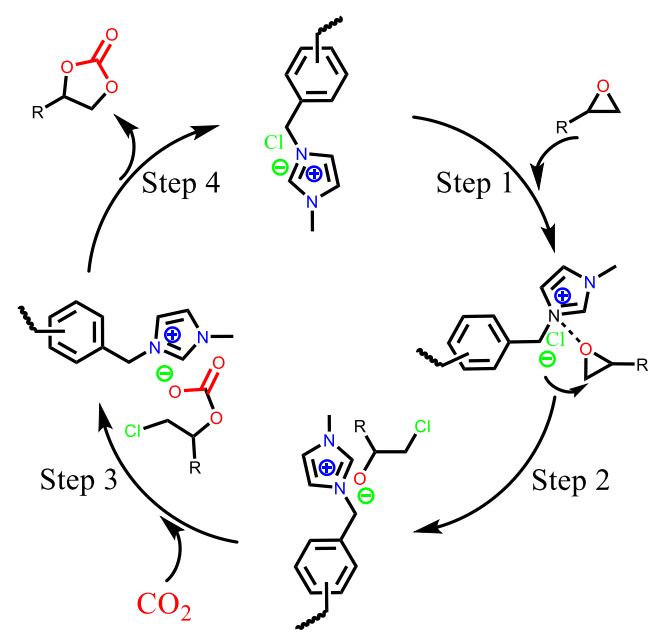

Scheme 2. Plausible mechanism for $\left[\mathrm{HCP}-\mathrm{CH}_{2}-\mathrm{Im}\right][\mathrm{Cl}]-1$ catalyzed $\mathrm{CO}_{2}$ cycloaddition with epoxides

\section{Experimental Section}

\subsection{Materials}

The commercial chemicals and reagents were used as received without further purification unless otherwise stated. Allyl chloride (98\%), diphenyl (99\%), dichloroethane (DCE, 99\%), dimethoxy methane (FDA, 98\%), 1-methylimidazole (99\%), epichlorohydrin (AR), allyl glycidyl ether (99\%), butyl glycidyl ether $(98 \%)$, propylene oxide $(99 \%)$, and o-Tolyl glycidyl ether (90\%) were provided by Aladdin Chemical Reagent Co. LTD (Beijing, China). Sulfuric acid (98\%), ferric chloride $\left(\mathrm{FeCl}_{3}, 98 \%\right)$, and ethyl acetate (EtOAc, AR) were purchased from Sinopharm Chemical Reagent Co. LTD. Styrene oxide (98\%), glycidyl phenyl ether (99\%), and 1,2-ethylene dibromide (98\%) were purchased from Energy Chemical Reagent Co., Ltd. (Shanghai, China).

\subsection{Characterization}

The IR spectra were obtained using an FT-IR $\left(4000 \sim 400 \mathrm{~cm}^{-1}\right)$ spectrometer (Nicolet Nexus FT-IR spectrometer (Madison, WI USA) at $4 \mathrm{~cm}^{-1}$ resolution and 32 scans. NMR spectra were acquired in $\mathrm{CDCl}_{3}$ on a Bruker AVANCE III $500 \mathrm{MHz}$ spectrometer (Zurich, Switzerland) for ${ }^{1} \mathrm{H}$ NMR; the particular NMR spectra can be found in the Supplementary Material (Figures S3-S10). ${ }^{13} \mathrm{C}$ CP/MAS NMR spectra were measured on an AgilentNMR-VnmrS 600 (Palo Alto, CA, USA). Thermogravimetric analysis (TGA-50H, Shimadzu, Kyoto, Japan) of the samples was carried out: they were heated from 50 to $800{ }^{\circ} \mathrm{C}$ at ramp $10^{\circ} \mathrm{C} /$ min under Ar gas flow. Brunauer-Emmett-Teller (BET) pore volumes and surface areas were recorded with $\mathrm{N}_{2}$ adsorption at $77 \mathrm{~K}$ by using JWGB (JW-DEL 200 (Beijing, China). The crystal structure of the samples was examined by X-ray diffraction (XRD) on SmartLa. CHNS elemental analysis was performed on the Vario EL Cube. Field emission scanning electron microscope (FESEM; Hitachi S-4800, accelerated voltage: $5 \mathrm{kV}$ (Tokyo, Japan) was used to observe the morphology. Transmission electron microscope (TEM) images of the samples were examined by Hitachi H-7650 (Tokyo, Japan). X-ray photoelectron spectroscopy (XPS) of the [HCP-CH$-\mathrm{Im}][\mathrm{Cl}]-1$ was determined by Thermo Fisher Scientific K-alpha ${ }^{+}$(Waltham, MA, USA) equipped with Al K radiation (1486.68 eV).

\subsection{Synthesis of HCP}

A mixture of biphenyl (0.02 mol, $3.084 \mathrm{~g})$ and FDA $(5.3 \mathrm{~mL})$ in DCE $(50 \mathrm{~mL})$ was stirred for $10 \mathrm{~min}$ at room temperature. $\mathrm{FeCl}_{3}(9.732 \mathrm{~g}, 0.06 \mathrm{~mol})$ was then added and the mixture was heated to $80{ }^{\circ} \mathrm{C}$ for $24 \mathrm{~h}$. The resultant polymers were filtered and washed with methanol, and further purified for $24 \mathrm{~h}$ via Soxhlet extractions with methanol as solvent. The obtained HCP was vacuum-dried at $80{ }^{\circ} \mathrm{C}$ for $24 \mathrm{~h}$. 


\subsection{Synthesis of $\mathrm{HCP}-\mathrm{CH}_{2}-\mathrm{Cl}-\mathrm{X}$}

A mixture of HCP $(1 \mathrm{~g})$ and ethyl acetate $(40 \mathrm{~mL})$ was swelled at $60{ }^{\circ} \mathrm{C}$ and in 2 $\mathrm{h}$. Then the mixture was cooled to room temperature, and allyl chloride $(5.3 \mathrm{~mL})$ was added to the mixture. The ethyl acetate $(10 \mathrm{~mL})$ and sulfuric acid $(1.5 \mathrm{~g})$ were added to the mixture by using a constant pressure separatory funnel, and the reaction was carried out at $50{ }^{\circ} \mathrm{C}$ for $24 \mathrm{~h}$. After the reaction, the products were washed with ethyl acetate and deionized water and dried in a vacuum at $80{ }^{\circ} \mathrm{C}$ for $24 \mathrm{~h}$ to obtain $\mathrm{HCP}-\mathrm{CH}_{2}-\mathrm{Cl}-1$. The other $\mathrm{HCP}-\mathrm{CH}_{2}-\mathrm{Cl}-\mathrm{X}$ was synthesized similarly using the aforementioned procedures under different reaction conditions.

\subsection{Synthesis of [HCP-CH$-\mathrm{Im}][\mathrm{Cl}]-\mathrm{X}$}

A mixture of the $\mathrm{HCP}-\mathrm{CH}_{2}-\mathrm{Cl}-1(1 \mathrm{~g})$ and ethyl acetate was heated to $50{ }^{\circ} \mathrm{C}$ for $2 \mathrm{~h}$ for the swelling of the polymers and then 1-methylimidazole $(0.02 \mathrm{~mol}, 1.64 \mathrm{~g})$ was added to the mixture; the reaction was heated to $80{ }^{\circ} \mathrm{C}$ for $24 \mathrm{~h}$. The resultant polymers were washed with ethyl acetate and further dried under vacuum at $80^{\circ} \mathrm{C}$ for $24 \mathrm{~h}$. The other $\left[\mathrm{HCP}-\mathrm{CH}_{2}-\mathrm{Im}\right][\mathrm{Cl}]-\mathrm{X}$ was synthesized following the same procedure.

\subsection{General Catalytic Procedure for $\mathrm{CO}_{2}$ Cycloaddition to Epoxides}

In a typical run, styrene oxide (SO, $5 \mathrm{mmol})$ and $\left[\mathrm{HCP}-\mathrm{CH}_{2}-\mathrm{Im}\right][\mathrm{Cl}]-1(25 \mathrm{wt} \%)$ were charged into a high-pressure stainless steel autoclave (Figure S11), which was pressured with $\mathrm{CO}_{2}(0.1 \mathrm{MPa})$, and the reactant was heated to $140{ }^{\circ} \mathrm{C}$ for $5 \mathrm{~h}$. After the reaction and cooling to room temperature, the remaining $\mathrm{CO}_{2}$ was released slowly. The product was diluted with ethyl acetate and the liquid phase was separated via filtration. The ethylene dibromide $(0.5 \mathrm{mmol}, 36 \mu \mathrm{L})$ was added as the internal standard after the rotary evaporation of ethyl acetate. The yield and selectivity were analyzed via ${ }^{1} \mathrm{H}$ NMR.

\section{Conclusions}

A new strategy for synthesizing hypercrosslinked imidazolium-based ionic polymers with high ionic content and higher specific surface area from porous HCPs was developed through addition reaction and quaternization. The specific surface area and ionic content of HIPs could be adjusted by optimizing addition reaction conditions (the mass ratio of allyl chloride to $\mathrm{HCP}$, reaction temperature, the ratio of $\mathrm{H}_{2} \mathrm{SO}_{4} / \mathrm{HCP}$, and reaction time). FT-IR, solid-state ${ }^{13} \mathrm{C}$ NMR, XPS, and SEM mapping demonstrated that the HIPs were successfully prepared. The obtained HIP $\left[\mathrm{HCP}-\mathrm{CH}_{2}-\mathrm{Im}\right][\mathrm{Cl}]-1$ with high ionic content and higher specific surface area not only possessed good $\mathrm{CO}_{2}$ uptake but also exhibited outstanding catalytic yields for most epoxy substrates (99\% selectivity and $91-99 \%$ yield) at atmospheric pressure in a shorter reaction time (4-6 h) without cocatalyst, solvent, and additive. In addition, the catalyst $\left[\mathrm{HCP}-\mathrm{CH}_{2}-\mathrm{Im}\right][\mathrm{Cl}]-1$ demonstrated excellent reusability and stability after six run times. The high ionic content of HIPs provides more reaction sites and high microporosity that could enrich $\mathrm{CO}_{2}$, which contributes to the efficient conversion of $\mathrm{CO}_{2}$ into cyclic carbonates. This work provides a new strategy to synthesize imidazoliumbased HIPs with high catalytic activity from porous HCPs for the cycloaddition of $\mathrm{CO}_{2}$ with epoxides at atmospheric pressure. Furthermore, we determined that the coordination of ionic content and specific surface area is a crucial factor for high catalytic activity for the cycloaddition of $\mathrm{CO}_{2}$ with epoxides.

Supplementary Materials: The following are available online at https:/ /www.mdpi.com/article/ 10.3390 / catal12010062/s1, Figure S1: XRD patterns of HCP, $\mathrm{HCP}-\mathrm{CH}_{2}-\mathrm{Cl}-1$, [HCP-CH$\left.-\mathrm{IM}\right][\mathrm{Cl}]-1$; Figure S2: (a) $\mathrm{CO}_{2}$ adsorption isotherms of [HCP-CH$\left.-\mathrm{Im}\right][\mathrm{Cl}$ (1) at $273 \mathrm{~K}$ and $298 \mathrm{~K}$, (b) recycling performance of $\left[\mathrm{HCP}-\mathrm{CH}_{2}-\mathrm{Im}\right][\mathrm{Cl}]$ (1) at $273 \mathrm{~K}$. Figures S3-S10: ${ }^{1} \mathrm{H}$ NMR spectra of cyclic carbonates. Table S1: The effect of mass ratio of allyl chloride/HCP on specific surface area and chloromethyl content of $\mathrm{HCP}-\mathrm{CH}_{2}-\mathrm{Cl}-\mathrm{X}$; Table S2: The effect of mass ratio of $\mathrm{H}_{2} \mathrm{SO}_{4} / \mathrm{HCP}$ on specific surface area and chloromethyl content of $\mathrm{HCP}-\mathrm{CH}_{2}-\mathrm{Cl}-\mathrm{X}$; Table S3: The effect of reaction time on specific surface area and chloromethyl content of $\mathrm{HCP}-\mathrm{CH}_{2}-\mathrm{Cl}-\mathrm{X}$; Table S4: The effect of reaction temperature on 
specific surface area and chloromethyl content of $\mathrm{HCP}-\mathrm{CH}_{2}-\mathrm{Cl}-\mathrm{X}$; Table S5: The synthesis conditions of $\mathrm{HCP}-\mathrm{CH}_{2}-\mathrm{Cl}-\mathrm{X}$; Table S6: Textual properties of [HCP-CH$\left.-\mathrm{Im}\right][\mathrm{Cl}]-\mathrm{X}$; Table S7: Activity of porous ionic polymers in the cycloaddition of $\mathrm{CO}_{2}$ with styrene oxide.

Author Contributions: Conceptualization, X.L. (Xu Liao), B.P. and J.L.; methodology, X.L. (Xu Liao) and B.P.; investigation, X.L. (Xu Liao); resources, X.L. (Xu Liao), B.P. and J.L.; data curation, X.L. (Xu Liao), B.P., R.M., J.H., L.K. and X.G.; writing-original draft preparation, X.L. (Xu Liao); writing-review and editing, X.L. (Xu Liao), X.L. (Xiaoyan Luo) and J.L.; visualization, X.L. (Xu Liao) and J.L.; supervision, X.L. (Xiaoyan Luo) and J.L.; project administration, J.L.; funding acquisition, J.L. All authors have read and agreed to the published version of the manuscript.

Funding: Financial support from the National Natural Science Foundation of China (21803021, 21246008) and the Natural Science Foundation of Fujian Province (2020J01065).

Data Availability Statement: The data presented in this study are available on request from the corresponding author via e-mail: linlab505@hqu.edu.cn (J.L.).

Acknowledgments: This work was supported by the National Natural Science Foundation of China (21803021, 21246008) and the Natural Science Foundation of Fujian Province (2020J01065). The authors give thanks for the support of the Instrumental Analysis Center, Huaqiao University.

Conflicts of Interest: The authors declare that they have no known competing financial interests or personal relationships that could have appeared to influence the work reported in this paper.

\section{References}

1. Jia, D.; Ma, L.; Wang, Y.; Zhang, W.; Li, J.; Zhou, Y.; Wang, J. Efficient $\mathrm{CO}_{2}$ enrichment and fixation by engineering micropores of multifunctional hypercrosslinked ionic polymers. Chem. Eng. J. 2020, 390, 124652. [CrossRef]

2. Xie, Y.; Liang, J.; Fu, Y.; Huang, M.; Xu, X.; Wang, H.; Tu, S.; Li, J. Hypercrosslinked mesoporous poly(ionic liquid)s with high ionic density for efficient $\mathrm{CO}_{2}$ capture and conversion into cyclic carbonates. J. Mater. Chem. A. 2018, 6, 6660-6666. [CrossRef]

3. Zhang, W.; Ma, F.; Ma, L.; Zhou, Y.; Wang, J. Imidazolium-functionalized ionic hypercrosslinked porous polymers for efficient synthesis of cyclic carbonates from simulated flue gas. ChemSusChem 2020, 13, 341-350. [CrossRef] [PubMed]

4. Liu, Q.; Wu, L.; Jackstell, R.; Beller, M. Using carbon dioxide as a building block in organic synthesis. Nat. Commun. 2015, 6, 5933. [CrossRef]

5. Ma, D.; Liu, K.; Li, J.; Shi, Z. Bifunctional metal-free porous organic framework heterogeneous catalyst for efficient $\mathrm{CO}_{2}$ conversion under mild and cocatalyst-free conditions. ACS Sustain. Chem. Eng. 2018, 6, 15050-15055. [CrossRef]

6. Sang, Y.; Huang, J. Benzimidazole-based hyper-cross-linked poly(ionic liquid)s for efficient $\mathrm{CO}_{2}$ capture and conversion. Chem. Eng. J. 2020, 385, 123973. [CrossRef]

7. Zhang, Y.; El-Sayed, E.M.; Su, K.; Yuan, D.; Han, Z. Facile syntheses of ionic polymers for efficient catalytic conversion of $\mathrm{CO}_{2}$ to cyclic carbonates. J. CO2 Util. 2020, 42, 101301. [CrossRef]

8. Li, Y.D.; Cui, D.X.; Zhu, J.C.; Huang, P.; Tian, Z.; Jia, Y.Y.; Wang, P.A. Bifunctional phase-transfer catalysts for fixation of $\mathrm{CO}_{2}$ with epoxides under ambient pressure. Green Chem. 2019, 21, 5231-5237. [CrossRef]

9. Mosteirin, N.F.; Jehanno, C.; Ruiperez, F.; Sardon, H.; Dove, A.P. Rational study of DBU salts for the $\mathrm{CO}_{2}$ insertion into epoxides for the synthesis of cyclic carbonates. ACS Sustain. Chem. Eng. 2019, 7, 10633-10640. [CrossRef]

10. Xu, X.; Chen, C.; Guo, Z.; North, M.; Whitwood, A.C. Metal-and halide-free catalyst for the synthesis of cyclic carbonates from epoxides and carbon dioxide. ACS Catal. 2019, 9, 1895-1906.

11. Alves, M.; Grignard, B.; Mereau, R.; Jerome, C.; Tassaing, T.; Detrembleur, C. Organocatalyzed coupling of carbon dioxide with epoxides for the synthesis of cyclic carbonates: Catalyst design and mechanistic studies. Catal. Sci. Technol. 2017, 7, 2651-2684. [CrossRef]

12. Peng, J.; Yang, H.J.; Geng, Y.; Wei, Z.; Wang, L.; Guo, C.Y. Novel, recyclable supramolecular metal complexes for the synthesis of cyclic carbonates from epoxides and $\mathrm{CO}_{2}$ under solvent-free conditions. J. CO2 Util. 2017, 17, 243-255. [CrossRef]

13. Deacy, A.C.; Kilpatrick, A.F.R.; Regoutz, A.; Williams, C.K. Understanding metal synergy in heterodinuclear catalysts for the copolymerization of $\mathrm{CO}_{2}$ and epoxides. Nat. Chem. 2020, 12, 372-380. [CrossRef] [PubMed]

14. Andrea, K.A.; Butler, E.D.; Brown, T.R.; Anderson, T.S.; Jagota, D.; Rose, C.; Lee, E.M.; Goulding, S.D.; Murphy, J.N.; Kerton, F.M.; et al. Iron complexes for cyclic carbonate and polycarbonate formation: Selectivity control from ligand design and metal-center geometry. Inorg. Chem. 2019, 58, 11231-11240. [CrossRef]

15. Yang, H.Q.; Chen, Z.X. Theoretical investigation on conversion of $\mathrm{CO}_{2}$ with epoxides to cyclic carbonates by bifunctional metal-salen complexes bearing ionic liquid substsituents. Mol. Catal. 2021, 511, 111733. [CrossRef]

16. Benedito, A.; Acarreta, E.; Gimenez, E. A highly efficient $\mathrm{MOF}$ catalyst systems for $\mathrm{CO}_{2}$ conversion to bis-cyclic carbonates as building blocks for NIPHUs (non-isocyanate polyhydroxyurethanes) synthesis. Catalysts 2021, 11, 628. [CrossRef]

17. Akimana, E.; Wang, J.; Likhanova, N.V.; Chaemchuen, S.; Verpoort, F. MIL-101(Cr) for $\mathrm{CO}_{2}$ conversion into cyclic carbonates under solvent and Co-catalyst free mild reaction conditions. Catalysts 2020, 10, 453. [CrossRef] 
18. Liang, L.; Liu, C.; Jiang, F.; Chen, Q.; Zhang, L.; Xue, H.; Jiang, H.L.; Qian, J.; Yuan, D.; Hong, M. Carbon dioxide capture and conversion by an acid-base resistant metal-organic framework. Nat. Commun. 2017, 8, 1233. [CrossRef]

19. Pander, M.; Janeta, M.; Bury, W. Quest for an efficient 2-in-1 MOF-based catalytic system for cycloaddition of $\mathrm{CO}_{2}$ to epoxides under mild conditions. ACS Appl. Mater. Interfaces 2021, 13, 8344-8352. [CrossRef]

20. Abazari, R.; Sanati, S.; Morsali, A.; Kirillov, A.M.; Slawin, A.M.Z.; Carpenter-Warren, C.L. Simultaneous presence of open metal sites and amine groups on a 3D Dy(III)-metal-organic framework catalyst for mild and solvent-free conversion of $\mathrm{CO}_{2}$ to cyclic carbonates. Inorg. Chem. 2021, 60, 2056-2067. [CrossRef]

21. Zhang, Y.; Xu, W.G.; Han, Z.B. MOF@POP core-shell architecture as synergetic catalyst for high-efficient $\mathrm{CO}_{2}$ fixation without cocatalyst under mild conditions. J. CO2 Util. 2021, 46, 101463. [CrossRef]

22. Yu, W.; Gu, S.; Fu, Y.; Xiong, S.; Pan, C.; Liu, Y.; Yu, G. Carbazole-decorated covalent triazine frameworks: Novel nonmetal catalysts for carbon dioxide fixation and oxygen reduction reaction. J. Catal. 2018, 362, 1-9. [CrossRef]

23. Siewniak, A.; Forajter, A.; Szymanska, K. Mesoporous silica-supported ionic liquids as catalysts for styrene carbonate synthesis from $\mathrm{CO}_{2}$. Catalysts 2020, 10, 1363. [CrossRef]

24. Wang, J.; Zhang, Y. Facile synthesis of N-rich porous azo-linked frameworks for selective $\mathrm{CO}_{2}$ capture and conversion. Catalysts 2020, 10, 1363. [CrossRef]

25. Wang, X.; Dong, Q.; Xu, Z.; Wu, Y.; Gao, D.; Xu, Y.; Ye, C.; Wen, Y.; Liu, A.; Long, Z.; et al. Hierarchically nanoporous copolymer with built-in carbene- $\mathrm{CO}_{2}$ adducts as halogen-free heterogeneous organocatalyst towards cycloaddition of carbon dioxide into carbonates. Chem. Eng. J. 2021, 403, 126460. [CrossRef]

26. Li, Y.; Zhang, J.; Zuo, K.; Li, Z.; Wang, Y.; Hu, H.; Zeng, C.; Xu, H.; Wang, B.; Gap, Y. Covalent organic frameworks for simultaneous $\mathrm{CO}_{2}$ capture and selective catalytic transformation. Catalysts 2021, 11, 1133. [CrossRef]

27. Huang, K.; Zhang, J.Y.; Liu, F.; Dai, S. Synthesis of porous polymeric catalysts for the conversion of carbon dioxide. ACS Catal. 2018, 8, 9079-9102. [CrossRef]

28. Ding, M.; Jiang, H.L. Incorporation of imidazolium-based poly(ionic liquid)s into a metal-organic framework for $\mathrm{CO}_{2}$ capture and conversion. ACS Catal. 2018, 8, 3194-3201. [CrossRef]

29. Song, H.; Wang, Y.; Xiao, M.; Liu, L.; Liu, Y.; Liu, X.; Gi, H. Design of novel poly(ionic liquids) for the conversion of $\mathrm{CO}_{2}$ to $\mathrm{cyclic}$ carbonates under mild conditions without solvent. ACS Sustain. Chem. Eng. 2019, 7, 9489-9497. [CrossRef]

30. Subramanian, S.; Oppenheim, J.; Kim, D.; Nguyen, T.; Silo, W.; Kim, B.; Goddard, W.; Yavuz, C. Catalytic non-redox carbon dioxide fixation in cyclic carbonates. Chem 2019, 5, 3232-3242. [CrossRef]

31. Shen, R.; Yan, X.; Guan, Y.J.; Zhu, W.; Li, T.; Liu, X.G.; Li, Y.; Gu, Z.G. One-pot synthesis of a highly porous anionic hypercrosslinked polymer for ultrafast adsorption of organic pollutants. Polym. Chem. 2018, 9, 4724-4732. [CrossRef]

32. Suo, X.; Huang, Y.; Li, Z.; Pan, H.; Gui, X.; Xing, H. Construction of anion-functionalized hypercrosslinked ionic porous polymers for efficient separation of bioactive molecules. Sci. China Mater. 2021. [CrossRef]

33. Song, H.; Wang, Y.; Liu, Y.; Chen, L.; Feng, B.; Jin, X.; Zhou, Y.; Huang, T.; Xiao, M.; Huang, F.; et al. Conferring poly(ionic liquid)s with high surface areas for enhanced. ACS Sustain. Chem. Eng. 2021, 9, 2115-2128. [CrossRef]

34. Wang, J.; Sng, W.; Yi, G.; Zhang, Y. Imidazolium salt-modified porous hypercrosslinked polymers for synergistic $\mathrm{CO}_{2}$ capture and conversion. Chem. Commun. 2015, 51, 12076-12079. [CrossRef] [PubMed]

35. Pei, B.; Xiang, X.; Liu, T.; Li, D.; Zhao, C.; Qiu, R.; Chen, X.; Lin, J.; Luo, X. Preparation of chloromethylated pitch-based hyper-crosslinked polymers and an immobilized acidic ionic liquid as a catalyst for the synthesis of biodiesel. Catalysts 2019, 9, 963. [CrossRef]

36. Gan, Y.; Chen, G.; Sang, Y.; Zhou, F.; Man, R.; Huang, J. Oxygen-rich hyper-cross-linked polymers with hierarchical porosity for aniline adsorption. Chem. Eng. J. 2019, 368, 29-36. [CrossRef]

37. Puthiaraj, P.; Ravi, S.; Yu, K.; Ahn, W.S. $\mathrm{CO}_{2}$ Adsorption and conversion into cyclic carbonates over a porous $\mathrm{ZnBr}_{2}$-grafted N-heterocyclic carbene-based aromatic polymer. Appl. Catal. B Environ. 2019, 251, 195-205. [CrossRef]

38. Zhang, Y.; Zhao, L.; Patra, P.K.; Hu, D.; Ying, J.Y. Colloidal poly-imidazolium salts and derivatives. Nano Today 2009, 4, 13-20. [CrossRef]

39. Li, J.; Jia, D.; Guo, Z.; Liu, Y.; Lyu, Y.; Zhou, Y.; Wang, J. Imidazolinium based porous hypercrosslinked ionic polymers for efficient $\mathrm{CO}_{2}$ capture and fixation with epoxides. Green Chem. 2017, 19, 2675-2686. [CrossRef]

40. Chen, G.; Zhang, Y.; Xu, J.; Liu, X.; Liu, K.; Tong, M.; Long, Z. Imidazolium-based ionic porous hybrid polymers with POSSderived silanols for efficient heterogeneous catalytic $\mathrm{CO}_{2}$ conversion under mild conditions. Chem. Eng. J. 2020, $381,122765$. [CrossRef]

41. Guo, Z.; Jiang, Q.; Shi, Y.; Li, J.; Yang, X.; Hou, W.; Zhou, Y.; Wang, J. Tethering dual hydroxyls into mesoporous poly(ionic liquid)s for chemical fixation of $\mathrm{CO}_{2}$ at ambient conditions: A combined experimental and theoretical study. ACS Catal. 2017, 7, 6770-6780. [CrossRef]

42. Thommes, M.; Kaneko, K.; Neimark, A.V.; Olivier, J.P.; Rodriguez-Reinoso, F.; Rouquerol, J.; Sing, K.S.W. Physisorption of gases, with special reference to the evaluation of surface area and pore size distribution (IUPAC Technical Report). Pure Appl. Chem. 2015, 87, 1051-1069. [CrossRef]

43. Xie, Y.; Sun, Q.; Fu, Y.; Song, L.; Liang, J.; Xu, X.; Wang, H.; Li, J.; Tu, S.; Lu, X.; et al. Sponge-like quaternary ammonium-based poly(ionic liquid)s for high $\mathrm{CO}_{2}$ capture and efficient cycloaddition under mild conditions. J. Mater. Chem. A 2017, 5, 25594-25600. [CrossRef] 
44. Liu, F.; Huang, K.; Wu, Q.; Dai, S. Solvent-free self-assembly to the synthesis of nitrogen-doped ordered mesoporous polymers for highly selective capture andconversion of $\mathrm{CO}_{2}$. Adv. Mater. 2017, 29, 1700445. [CrossRef] [PubMed]

45. Ema, T.; Miyazaki, Y.; Shimonishi, J.; Maeda, C.; Hasegawa, J.Y. Bifunctional porphyrin catalysts for the synthesis of cyclic carbonates from epoxides and $\mathrm{CO}_{2}$ : Structural optimization and mechanistic study. J. Am. Chem. Soc. 2014, 136, 15270-15279. [CrossRef]

46. Luo, R.; Zhou, X.; Chen, S.; Li, Y.; Zhou, L.; Ji, H. Highly efficient synthesis of cyclic carbonates from epoxides catalyzed by salen aluminum complexes with built-in " $\mathrm{CO}_{2}$ capture" capability under mild conditions. Green Chem. 2014, 16, 1496-1506. [CrossRef]

47. Zhang, Y.; Yang, D.H.; Qiao, S.; Han, B.H. Synergistic catalysis of ionic liquid-decorated covalent organic frameworks with polyoxometalates for $\mathrm{CO}_{2}$ cycloaddition reaction under mild conditions. Langmuir 2021, 37, 10330-10339. [CrossRef]

48. Guo, Z.; Cai, X.; Xie, J.; Wang, X.; Zhou, Y.; Wang, J. Hydroxyl-exchanged nanoporous ionic copolymer toward low-temperature cycloaddition of atmospheric carbon dioxide into carbonates. ACS Appl. Mater. Interfaces 2016, 8, 12812-12821. [CrossRef] 